\title{
Mobilidades e territórios impensáveis. Contranarrativas e afetos de cabo-verdianos nas roças de São Tomé e Princípe
}

\section{Carla Indira Semedo}

Universidade Jean Piaget de Cabo Verde

Cidade da Praia, Ilha de Santigo, Cabo Verde

diracarvalho@gmail.com

ORCID: https://orcid.org/ 0000-0001-6756-1599

Cabo Verde aparece na memória social e nas práticas de pessoas cabo-verdianas enquanto um território atravessado e costurado pelas mobilidades a outros territórios, desde Europa, Américas e África. Dos vários territórios possiveis, São Tomé e Principe foi e continua sendo narrado como um território impensável. As multiplas narrativas elaboradas sobre os cabo-verdianos em São Tomé e Principe, quer os que experimentaram o acontecimento do trabalho contratado, quer os descendentes dessa experiência atroz, foi inscrita numa chave de regime depreciativo, criando nesse processo de produção de verdades, tentativas de silenciamento de vidas e narrativas que não importam. Em recusa, esse coletivo mostra como, no seu quotidiano, cria múltiplas contranarrativas reversas às narrativas hegemónicas, sinalizando não somente que não cabe nessa história narrada e, que ainda se narra, como também vidas foram construídas. E, as artes culinárias constituem, também, um desses lugares onde tais contranarrativas são elaboradas.

Unthinkable mobilities and territories. Counter-narratives and affections of Cape Verdeans in the fields of São Tomé and Princípe

ABSTRACT Cape Verde appears in the social memory and practices of cape verdeans as a territory crossed and sewn by mobilities to other territories, from Europe, the Americas and Africa. Of the various possible territories, São Tomé and Princípe was and continues to be narrated as an unthinkable territory. The many narratives elaborated on the cape verdeans in São Tomé and Princípe, both those who experienced the event of hired labor and the descendants of this atrocious experience, were inscribed in a derogatory key. If, on the one hand, the cape verdean migration to São Tomé e Príncipe farmsteams disturbs and stresses the heated debates about cape verdean identity, and the portrait of the "silenced black past" has been chosen, creating in this process of producing truths, attemps to silence lives and narratives that do not matter. In refusal, this coletive shows how, in its daily life, creates multiple counter-narratives, signaling not only that it does not fit in this history narrates, but also lives were built. The culinary arts are also onde of those places were such counter-narratives are elaborated.

KEYWORDS

Mobilities, counter-narratives, culinary arts, Cape Verde, São Tomé and Princípe 
Em finais dos anos quarenta (1947), Nha Maria Francisca, cabo-verdiana, "santa praça"1 no navio Ambrizete e, junta-se à lista dos cabo-verdianos aliciados pela Administração Colonial Portuguesa, à necessidade de contratar-se para as roças santomenses, publicado no Boletim Oficial de São Tomé a 28 de fevereiro de 1903. Conforme esse decreto, o processo de recrutamento da mão-de-obra barata e "escravizada" nas então colónias, Moçambique, Angola e Cabo Verde, visava: "salvaguardar as roças de monocultura de café e posteriormente de cacau", após a abolição da escravatura em 1869. Décadas volvidas, nos anos trinta do século XX, essa rede ultramarina intensifica-se com a criação de uma entidade jurídica: a Sociedade de Migração para São Tomé e Príncipe-SOEMI, que visava representar os interesses dos então donos das roças - os roceiros e, garantir o recrutamento dos contratados ${ }^{2}$.

Embora, nos inícios do século XX, após várias pressões internacionais face à denúncia da escravidão naquele arquipélago, tenha-se revisto os mecanismos de recrutamento e, uma maior observância dos contratos, somente nos inícios dos anos sessenta - em 1962, viria-se a criar o Código do Trabalho Rural. Nota-se que, os contratos e os processos de recrutamento passaram a operar noutras chaves e, conforme as narrativas dos cabo-verdianos em situação de contrato alusivas ao quotidiano nas roças: "trabalho duro, mas não encontrou porrada, como antigamente", mas, continuava a ser deshumano e atroz. Pois, em paralelo com o recrudescimento, no espaço cabo-verdiano, do capitalismo colonial das corporações/companhias agrárias e dos decretos-leis, a escravidão e relações escravistas permaneciam e irrompiam as relações sociais nas roças de São Tomé e Princípe. Relações ancoradas ao processo de criação do enunciado de que, a "única saída possível" a um quotidiano de fomes e, a eminência de mortes, era a evasão e o "alistamento" às roças santomenses ${ }^{3}$. Conforme, os informes demográficos de Carreira (1984: 177), Cabo Verde, em 1947, com a população em cerca de 160.000 habitantes, 128.000 (80\%) eram tidos como os "necessitados" do país: a força de trabalho contratada em potência.

Diante disso, o território Cabo Verde experimentava os efeitos do capitalismo moderno, tentativas de práticas escravistas irrompiam na vida das pessoas cabo-verdianas em pleno século XX, décadas após o período abolicionista. As narrativas dos cabo-verdianos que se alistaram e experimentaram o trabalho contratado nas roças santomenses de 1940 a 1970 e, os descendentes dessa experiência atroz, denunciam o facto de que, a despeito da abolição da escravatura no território português, a governamentalidade colonial portuguesa criou e, instaurou nas roças santomenses de café e cacau, um espaço onde vidas e trabalhos foram escravizados: mão-de-obra de pessoas oriundas das então colónias, em pleno século XX. As precárias condições nos porões dos navios: "gente vinha no porão como saco", as configurações espaciais das roças e das 'senzalas', as normas rígidas e deshumanas de funcionamento nas senzalas, o 'castigo' do trabalho no mato, a violência, os maus-tratos e, a impossibilidade de dispor da própria existência, por
1 | A expressão em crioulo cabo-verdiano "santa praça" é usada, comunemente, em alusão à migração contratada para trabalhar nas roças de São Tomé e Príncipe, equivalendo o movimento de alistamento para São Tomé e Príncipe à vida militar: assentar praça, ou alistar para a vida militar.

2 0 artigo recupera os dados da pesquisa etnográfica no âmbito do doutorado em Antropologia Social pelo Programa de Pós-Graduação em Antropologia Social da Universidade Federal do Rio de Janeiro/Museu Nacional, com apoio de bolsa Capes PEC-PC A tese debruç-se sobre a comunidade cabo-verdiana residente nas roças de São Tomé e Príncipe, explorando tanto as narrativas dessa migração, como também as experiências vividas e, experienciadas no presente tempo etnográfico.

3| Os contratoa administrativo para as roças de São Tomé e Príncipe, existentes nos arquivos, apontam para milhares de cabo-verdianos que, desde dos finais do século XIX até o último quartel do século XX se inscreveram na lista dos que foram aliciados à necessidade de se contratar para as roças santomenses, com a homologação dos enunciados jurídico-oficiosos. 
ser pessoa em situação de contrato, povoam as narrativas e as experiências dos meus interlocutores ${ }^{4}$.

Também, por se encontrar acoplado a uma gestão dos corpos e, de relações marcadas por um intenso adestramento de pessoas em situação de contrato, a fim de garantir a produção econômica das roças sob fortes e duras regras e punições, reitera a constatação de que a realização do trabalho conforme esperado e, definido pelos roceiros era a única garantia possível de escape às duras e fortes punições corporais.

Partindo deste panorâma de relações, afetos e experiências violentadamente marcadas por tentativas de atualização do acontecimento da escravidão, o presente artigo visa mostrar as múltiplas narrativas criadas, quer pelos 'descendentes' em São Tomé e Princípe, quer na historiografia e dos inteletuais cabo-verdianos. Para tal, proponho perceber como nas contranarrativas alternativas e singulares do coletivo cabo-verdiano 'descendente' dessa migração, a historiografia hegemónica é atualizada e apropriada. E, num segundo momento, mostrar como as artes culinárias poderão estar se constituindo numa contranarrativa em relação à narrativa historiográfica e, à memória social cabo-verdiana. Pois, nos possibilita perceber as contrarrativas, a gramática de emoções e, os afetos criados na roça, entretecidos e fortalecidos pelas/ nas artes culinárias "da terra". Pretendo com isso, sinalizar em como, não somente não cabem na única história que deles fora narrada e, ainda se narra, como também vidas foram construídas a despeito do que foram a experiência e os efeitos do acontecimento dessa migração.

\section{“A MIGRAÇÃO PARA O SUL”... NARRATIVAS DE TERRITÓRIOS IMPENSÁVEIS}

No território geopolítico cabo-verdiano, é recorrente momentos de histórias dos/com os então cabo-verdianos na condição de contratados, de como a família desconhece o destino de um familiar contratado, trinta, quarenta ou sessenta anos após o contrato para Sul. As histórias, concebo-as enquanto narrativas da ordem do acontecimento e do vivido, recriadas nas narrativas orais e, que escapam às narrativas hegemónicas de construção do Estado cabo-verdiano. E, em muitas dessas histórias há um movimento de, em certa medida, atualizar os regimes de verdade criados pela administração colonial e, pelos cabo-verdianos letrados da época, entre as quais o de que, a migração cabo-verdiana para São Tomé e Príncipe - 'santa praça' - equipara-se a uma "condenação a degredo":

A ida dos cabo-verdianos para as roças de São Tomé e Príncipe foi sempre considerada no arquipélago como uma deportação ou mais propriamente uma condenação a degredo - sem se ter cometido crime algum. Tanto é assim que não se dizia que alguém embarcou para S.Tomé, mas que 'embarcou para o Sul', alusão ao envio de condenados de delitos comuns pelos Tribunais ordinários para Angola, onde iam cumprir penas-como era corrente. Por outro lado, no consenso geral o 'dar nome' ao agente recrutador para a
4 | A pesquisa etnográfica decorreu exclusivamente na Ilha de São Tomé de janeiro a julho de 2013 e de novembro de 2014 a janeiro de 2015. Busquei o registro das narrativas dos idosos cabo-verdianos alusivas à experiência da migração contratada, pesquisas nos arquivo do Arquivo Histórico Nacional de São Tomé e de Cabo Verde e, etnografar o quotidiano e as relações do coletivo cabo-verdiano residente na Roça Agostinho Neto. 
efetivação do contrato de trabalho para São Tomé e Príncipe, correspondia a uma autocondenação. O contrato para o Sul era o último recurso a lançar mão, uma vez reconhecida a impossibilidade de emigrar para qualquer outro país (Carreira, 1984: 175).

Por ter sido e, continuar a ser percebida sob o signo "duma má migração, a que não teve sucesso" no imaginário social dos cabo-verdianos, foi e ainda é a migração da qual mais se fal(a)ou, sobre a qual e com a qual, produziu-se narrativas e enunciados nos lugares e momentos de enunciação diferenciados e, por coletivos também variados. Entretanto, esta proliferação e exaltação das discursividades e enunciações estiveram sempre ancoradas numa chave depreciativa: a "migração de condenados", "condenados pela fome" e "condenados a ir para o Sul": a África, ao invés do sonho doirado do emigrante" de Cabo Verde. Exemplo disso é o trecho da narrativa musical do compositor cabo-verdiano Code di Dona, o qual também se alistara, na altura, para o contrato: "Quem tem dinheiro já foi para Holanda/ Quem está em uma situação económica boa já foi para Lisboa/ Mas quem está em uma condição razoável foi para Angola"/ "Os desanimados assentaram praça [foram para São Tomé e Príncipe]"5.

Outrossim, segundo a pequena burguesia cabo-verdiana - os grandes donos das terras, os comerciantes, os intelectuais, maioria mestiça - esse fluxo de corpos e ideias para São Tomé e Príncipe poderia se traduzir numa impossibilidade da atualização da tão almejada 'europeização do cabo-verdiano'. Eugénio Tavares, figura da vida cultural, política e social de Cabo Verde entre 1890 e 1930, prosista e poeta de índole social, chama a atenção para as injustiças ao "povo cabo-verdiano", para os efeitos da migração para São Tomé, entre os quais, tornar esse povo "uma espécie de contratado de S.Tomé" enredado em relações escravistas:

\footnotetext{
Proibir a migração cabo-verdiana para os Estados Unidos é dirigirmo-nos ao povo caboverdiano, e dizer-lhe: amigo tira os sapatos; despe o casaco; pega na enxada e salta para os morgadios de Santiago, do Fogo, de Santo Antão, onde há falta de braços. Foste, até aqui, o livre trabalhador da América: de agora passas a ser uma espécie de contratado de S.Tomé. Até hoje comeste à tua mesa, em pratos e com talheres, o pão que o suor do teu rosto livremente fecundou e madureceu: de hoje em diante irás comer em panelas de pau; o pão que o diabo amassou - dessa escravidão encarnizada de liberdade, que é um insulto à dignidade humana. (Eugénio Tavares, 1918 apud Furtado, 1987: 62)
}

A MIGRAÇÃO

(A propósito da migração para S. Tomé e Príncipe)

Como é triste e é desolador Ver partir, aos magotes, esta gente
5| Narrativa musical em crioulo cabo-verdiano: "Ki tem dinheru dja ka bai Holanda/ Ki sta na djetu já ka bai Lisboa/Ma ramediadus dja ka bai Angola/ Desanimados dja ka Santa Praça". 
A tanto sofrimento, tanta dor!

Se a sorte ainda a traz à terra amiga

Macilenta, tristonha, depauperada,

Com a doença do sono, já minada,

Ao cemitério um só coval mendiga!

Mas porque ides, assim arrebanhada,

A essa maldita terra de desterro?

É a fome que vos leva acorrentada?

Aproveita melhor a mocidade

E ide mais distante, ide à América,

À terra do trabalho e liberdade!

(Orion)

Eugénio Tavares (1912)

Essa experiência de mobilidades tão presente na vivência dos cabo-verdianos, volvidos séculos, ainda é perceptível. Os últimos dados estatísticos reiteram a confirmação de Cabo Verde como um país de migração: se internamente a população é pouco mais de meio milhão de habitantes, na diáspora, os dados dão conta dum número superior de 'descendente de cabo-verdianos' (Censo 2010, INE). Poderia até ser caricato ou retórico perguntar a um/a cabo-verdiano/a se teria familiar na migração, pois a resposta será sempre: "claro todo mundo (cabo-verdiano) o tem"! As práticas quotidianas das pessoas reverberam tempos e espaços de migrar: tempo alimentado entre os que ficaram na terra de origem e aguardam aventurar-se para a "terra prometida"; espaços que são criados diariamente a partir da materialidade dos objetos (encomenda aos que estão fora, os trazidos/enviados pelos familiares retornados) entre os familiares dos migrantes, como forma de reforçar a proximidade das relações familiares e os afetos a despeito da distância fisico-geográfica (Lobo, 2006).

Os enunciados históricos, com os quais tenho dialogado, situam os primórdios desse fluxo de corpos e desejos, entre os finais do século XIX e inícios do século $\mathrm{XX}$, recorrendo ao que convido a pensar: as vulnerabilidades ecológica e ambiental (clima árido e escassez de chuvas), com vista a entender esse fenómeno intenso que atravessa, ainda, a corporeidade da pessoa cabo-verdiana-as mobilidades (Carreira, 1977; Carreira, 1983; Andrade, 1995). Inicialmente, o destino foi às Américas (Estados Unidos da América) nas então embarcações pesqueiras de baleia e, posteriormente para São Tomé e Príncipe e Angola. Se inicialmente, o horizonte era a dita 'civilização' que as Américas e, a Europa prometiam, paulatinamente, a administração colonial 
direciona os caminhos para as roças santomenses, limitando o fluxo para os outros continentes, até os finais do anos 50 do século XX.

A despeito de que, comumente se percebe a diáspora cabo-verdiana como uma extensão à Nação do Estado Cabo Verde, uma nação que borra as fronteiras geopolíticas, entendo que por detrás dessa "homogeneidade", emanam questões relevantes que mostram uma diáspora mais heterogénea, multiforme e narrada em chaves diversas. Ao homogeneizá-la, invisibilizam-se as diversas histórias das migrações cabo-verdianas, o facto de que o destino da migração, a conjuntura da migração e as práticas discursivas criadas sobre e com essas experiências subsidiam registos essenciais para enfrentar essa "homogeneidade": caso da diáspora cabo-verdiana em São Tomé e Príncipe. Um pouco por todos os arquivos históricos, em decretos leis e, nas criações músico-literárias cabo-verdianas, criaram-se variações nos modos de narrar, como narrar e o que narrar da experiência migratória das pessoas cabo-verdianas. Entendo que, a migração cabo-verdiana tem sido associada aos modelos explicativos, nos quais as fomes e, as secas são produzidas enquanto vetores de mobilidade espacial, em simultâneo com a elaboração de práticas discursivas da migração, como a única saída possível diante da miséria nos segmentos rurais e urbanos mais empobrecidos. Também, observo que as fomes e as secas, como acontecimentos, criaram outros acontecimentos, outras práticas discursivas e objetos de enunciação centrais no entendimento do que se nomeou como a "migração contratada dos cabo-verdianos" para São Tomé e Príncipe.

A migração cabo-verdiana para o continente africano, numa modalidade de migração laboral contratada, foi numa primeira onda para São Tomé e Príncipe e, em seguida para a Angola. Apesar da migração para Angola ter sido similar, àquela às roças santomenses foi acoplada às narrativas de silenciamento, lugares de enunciação onde práticas capitalistas foram embaciadas e substituídas pela "fuga à seca e fome", "arranjar seu dinheirinho e voltar melhor para terra": afinal "três ou quatro anos passam-se rápidos, e pelo menos não faltará a banana, a fruta-pão e o azeite de palma." (Vieira, 1951: 32). Ainda sobre o imaginário de "condenação a degredo" para pensar e criar relações com essa migração, observamos que a dita "migração cabo-verdiana para o Sul" deslocaria e tensionaria conceções de pessoa e de corporeidade já dadas e criadas pela e na cartografia das relações sociais da época. Uma cartografia na qual o capital simbólico do colonialismo acionado pelo cabo-verdiano o aproximaria ao colonizador português e, por conseguinte, se constituiria menos "colonizado", menos "indígena", "selvagem" e africano disseminando um capital simbólico alimentado por certo sentimento de superioridade cultural e racial distanciado-o dos das outras colónias portuguesas.

Assim, o possível e acordado nível cultural e civilizacional possuído pelos cabo-verdianos desvanecer-se-ia na relação com os outros então serviçais (esses, nessa cosmovisão, os "africanos") nas roças, tal como o estatuto de indigenato. Aparentemente 
destituído em Cabo Verde, percebe-se de uma tentativa de atualização do estatuto de indigenato pelas condições de trabalho e, as condições de retorno dos cabo-verdianos em situação de contrato: não retornando nem melhor, nem superior, mas um cabo-verdiano africano. Nessa chave, meu argumento é que a figura do contratado, o migrante do Sul ao retornar, por estar evocando e reatualizando o passado escravista e a africanidade dos cabo-verdianos, tão renegada e impensável: "de hoje em diante irá comer em panelas de pau; o pão que o diabo amassou - dessa escravidão encarnizada de liberdade, que é um insulto à dignidade humana", foi sendo resignificada na migração impensável.

Outrossim, as mobilidades para o arquipélago santomense intensificariam o debate de que as noções nacionalistas e identitárias do povo e da sociedade de Cabo Verde foram sendo construídas num embate África versus Europa (Dos Anjos, 2006; Fernandes, 2002; Furtado, 1987). Numa base onde a África, o Continente Africano era 'diluído', era renegado ao ponto da identidade racial ser continuum à conceção de Nação e do Estado: "Ser Cabo-verdiano e não ser africano", ao mesmo tempo em que, se projetavam possibilidades de uma aproximação Cabo Verde - Europa. Partindo do fato de que importa atentar como Foucault (2013: 100) sinalizou, para "o que se produziu pelo próprio fato de ter sido enunciado e precisamente esse enunciado (e nenhum outro) em circunstâncias bem determinadas", essas discursividades procedem por um certo grau de perversidade na criação dessa virtualidade existencial pelo colonialismo português. Pois:

\footnotetext{
a descaracterização das causas da migração esconde os verdadeiros motivos, colocando o suposto universalismo da cultura cabo-verdiana como fundamento à ida do cabo-verdiano a S.Tomé e Príncipe e outras partes do 'Além-Mar'. (Furtado, 1987: 69).
}

Com isso, a administração colonial viria a criar um discurso de que os cabo-verdianos transformar-se-iam em novos missionários: só que em vez de 'cristianizar', teriam por missão 'civilizar'." Ora, sendo desses a maioria despossuída do capital escolar (era recorrente o recurso a testemunhas para assinar a rogo e as impressões digitais do serviçal contratado, no contrato), como poderiam "transformar-se nos arautos da civilização europeia?" (Furtado, 1987).

Da mesma forma, que não fora percebida na chave do "tipo-ideal" migratório ao constranger e impossibilitar a objetificação dos afetos e desejos plasmados nos fluxos e, por se vê-la unicamente numa chave de um suposto "atraso cultural"; também, em nenhum momento, a criação e a propiciação de um deslocamento de corpos braçais inserido num sistema jurídico de trabalho "contratado escravo", foi mote para os inteletuais cabo-verdianos da época censurarem essa migração. O tão enfatizado dinamismo literário e cultural de Cabo Verde nos anos 30 e 40 do século passado protagonizado pelo movimento Claridoso, discortinando sobre a identidade cultural 
fundada na criação duma "cabo-verdianidade" e, a conjuntura socioeconómica e política das Ilhas, concebia esses no regime discursivo de que diante dos efeitos da seca, as fomes e as mortandades e, a evasão tornavam-se a única alternativa. Contudo, a urgência da migração para São Tomé e Príncipe, os efeitos devastadores na pessoa cabo-verdiana contratada, bem como a criação, pelo poder colonial português, dum movimento oportuno de migração para as roças santomenses, mediante a instrumentalização da realidade das fomes, não cabiam naquele dinamismo cultural e literário. Realço que entendo que houve instrumentalização da realidade das fomes pelo governo colonial em que, as narrativas coloniais sobre as fomes propiciaram a criação dos modos de existência e quotidianos de fomes, como mote para a migração, no caso para as roças santomenses, em que 'santar praça' constituiria "a única alternativa" às fomes e à eminência das mortandades. Percebe-se, assim, tentativas de transformá-las em realidades impensáveis, silenciadas e, das quais, não importava falar (Trouillot, 1995). Décadas volvidas, o ensaísta e político Onésimo Silveira, num ensaio em 1968, viria a tecer duras críticas:

\footnotetext{
Só se reflete nas obras dos claridosos o facto da migração para as Américas e jamais a migração degradante para as terras como S. Tomé e Príncipe, coexistente com aquela, mas que eles escritores, nunca desejariam para si mesmos. Só recentemente um deles, Baltazar Lopes, se mostrou preocupado com o tema desta última migração, em seu ciclo poético intitulado 'Romanceiro de S. Tomé', o qual, não obstante a expressão formal por vezes bela, apresenta uma intenção social bastante difusa. (1968: 11)
}

E, atualmente, uma breve e rápida revisitação aos arquivos (jornais e revistas) cabo-verdianos e santomenses, colocam-se os modos de existência nas roças num microcosmo despossuído da tão alcançada "modernidade", e narram-nos como se dum estado de natureza selvagem e, dum mundo residual da escravidão se tratassem. Títulos de artigos jornalísticos nos períodicos cabo-verdianos: "Pelas roças de São Tomé e Príncipe: Do nunca visto ao nem visto"; "Os cabo-verdianos em S.Tomé e Príncipe incomodam"; "Cabo-verdianos em S. Tomé e Príncipe: precariedade sem fim..."; "Cabo-verdianos em S. Tomé e Príncipe: Entre a pobreza extrema e o 'querer partir e ter de ficar" "; "Caminhu Longi"; "São Tomé e Príncipe é a experiência menos bem-sucedida nas migrações cabo-verdianas". Ou, trechos de artigos jornalísticos:

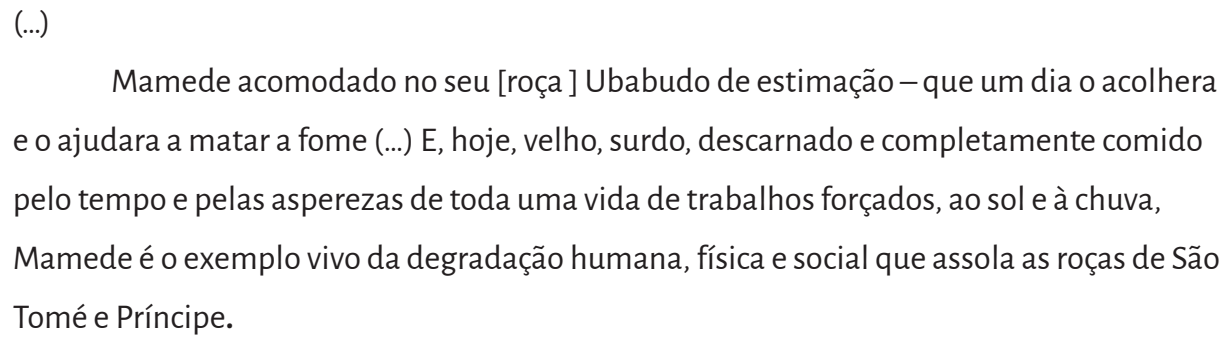


ARTIGo | Carla Indira Semedo | Mobilidades e territórios impensáveis. Contranarrativas e afetos

(...)

É no meio destes matos que se situam as roças onde vivem os cabo-verdianos e a maioria dos seus descendentes. Ali estão, no meio do mato, como bichos. A viverem em senzalas, a comer dos frutos do mato, a degradação humana é tanta que já nem acreditam que um dia as coisas poderão melhorar. São pessoas sem noções de comparação, porque vivem longe do progresso e evolução social, e sabem muito pouco do que se passa no mundo. Porque para eles o mundo é a floresta e os trabalhos nas parcelas concedidas pelo governo São-tomense." (Cardoso, 2010: 10)

Entretanto, de que forma a experiência do trabalho contratado eclodiu na vida de pessoas cabo-verdianas no território santomense? Em como esse território, apesar de, na época ter sido concebido na chave dum território impensável, povoado de experiências de dor e sofrimento, foi sendo povoado por afetos e relações outras, demandando e sinalizando formas outras de conceber a pessoa cabo-verdiana em São Tomé e Píncipe. Trago as narrativas e experiências desse coletivo, contranarrativas emancipatórias em rutura às narativas hegemónicas da esterilidade e, da decrepetude humana e material., um coletivo que a meio duma experiência atroz e violenta pôde criar outros modos existenciais, na forma como elaboram os pratos culinários e, demarcaram os lugares existenciais de ser"santomense descendente de cabo-verdianos",

\section{“(...) SE ELES VIVEM NAQUELA SITUAÇÃO, É VERDADE QUE NÃO}

\section{TÊM BOAS COISAS A DIZER.": AS CONTRANARRATIVAS}

Sadyel- Normalmente, quer dizer, eu acho que a imagem que tentam levar de São Toméé também um pouco pejorativa, de modo a denegrir também um pouco a vivência, a imagem das comunidades. De fato, que os cabo-verdianos passam aí, não é, dificuldade, então, eu acho eles vem somente afirmar aquilo que é mal, tá a ver, que os cabo-verdianos estão a viver. Mas há também muitos cabo-verdianos aqui que tão a viver muito bem, há filhos cabo-verdianos que já foram ministros, nãoé, ocuparam al tos cargos no governo. Mas, isso também eles não levam, tá a ver. Vem só buscar esta situação das comunidades mais desfavorecidas. Este é um forma também, pra mim eu acho que é um pouco negativo também. Nós devemos também ser mostrar as boas coisas, ou fazer junção das duas coisas, porque há cabo-verdiano aí no bairro de Hospital vivem, nãoé, vivem muito bem. Têm suas próprias casas, têm seus negócios. Há cabo-verdiano noutra zona que tem sua roça, não é, tem seus animais. Então eles vêm mais buscar de fato estas pessoas que, pronto, por infelicidade, não deram muito bem na vida, vivem uma situação mesmo lamentável, nãoé. Eu acho que devia mudar também um pouco o cenário.

Gualter-Realmente existe aquelas partes negativas, mas existe também muito boas coisas, não é, e nós aqui na comunidade de Agostinho Neto pode dizer realmente, nós somos provas disto. Existem alguns cabo-verdianos que vive sozinho, tem uma dificuldade em forma de viver, existem 
outros que filhos que estudaram, não têm assim grandes problemas na vida. Eles vêm, só preocupam em encontrar aquelas pessoas que naquela extrema forma de viver vive, então, é aqui que eles pegam, entrevista. E pronto, se eles vivem naquela situação, é verdade que eles não têm boas coisas a dizer, vivem naquelas formas, naquela dificuldade toda, de um pão que falta.

Sadyel-E não é só cabo-verdiano que vive nesta situação, se tu fores ver Santa Catarina, Praia Malanza, estas zonas, havia uma entrevista que eu assiste uma senhora mesmo santomense, natural, disse que há momentos ela de café da manhã o que ela come é coco, tá a ver, mostrou casa da senhora. Quer dizer não é só os cabo-verdianos é que vivem mal. Se subir esta zona de Lobata, vê casas que pessoas têm aqui, fala forro ${ }^{6}$, tem casas que gente dentro de casa, você na rua vê gente dentro de casa. Pelo menos, os cabo-verdianos têm estas casas de roças, tão mais seguros em relação a estas pessoas, forros mesmos. Há forro aí que tem casa, credo vento sopra, tá ver. É pra ver que não é só cabo-verdiano que tá a viver mal aqui.

Gualter-Pois duma forma geral, falando dos cabo-verdianos, falando dos santomenses, forro né, a boa parte da forma de estar dos cabo-verdianos, a forma negativa de ver, que vivem naquela situação extrema, isso tem muito a ver com a própria condição do País, tem muito a ver.

Excerto da conversa com Sadyel e Gualter, alusiva ao documentário "Os Últimos Contratados" (Leão Lopes, 2009).

Sadyel e Gualter, filhos e netos de cabo-verdianos que experimentaram a migração contratada, vivenciam quotidianamente os efeitos da "histórica única" que se fez não só dessa migração, como dos corpos, dos que a experimentaram. Recusam e insistem no fato de que se criou narrativas depreciativas e deshumanizantes dos cabo-verdianos em São Tomé. Como Sadyel pontua "eles vêm mais buscar de fato estas pessoas que, pronto, por infelicidade, não deram muito bem na vida, vivem uma situação mesmo lamentável".

Outrossim, aquilo que nomeio contranarrativas dos descendentes do acontecimento migração contratada/trabalho escravizado nas roças de São Tomé e Príncipe, sinalizam outros movimentos existenciais ao demandarem para si, um lugar de fala e outro lugar existencial de criação e, não desumanizante, criando outras relações de força. Pese embora, a condição de precariedade a que foram alocados, seja decorrente de falhas estruturais do país e, não seja exclusividade deles, insiste-se em conceber que a diáspora cabo-verdiana em São Tomé não cabe nas narrativas de sucesso e de modernidade visíveis nas outras comunidades diaspóricas.

As contranarrativas de Sadyel e Gualter chamam a atenção para aquilo que Chimamanda Adichie nomeou: o "perigo de uma única história" na qual se viram enredados e com a qual se insiste em falar sobre eles, como é demonstrado nas várias campanhas de solidariedade, nas reportagens jornalísticas e audiovisuais de que estariam "perdidos no mato", quando na verdade, eles se "veem vivendo remediado". Por instantes, o que Gualter e Sadyel sinalizam reverbera as falas de Adichie (s/d: 4):
6|A expressão 'Forro' é usada em São Tomé e Príncipe tanto em alusão ao nativo santomense, como em referência ao crioulo falado na llha de São Tomé. No arquipélago coexistem quatro crioulos reconhecidos oficialmente e usados nas conversações corriqueiras: 0 Forro da Ilha de São Tomé, o Lingué da llha do Príncipe, o Angolar dos angolares (um grupo étnico específico cuja presença originária é explicada por vários mitos fundantes) e o Crioulo Cabo-verdiano. 
ARTIGo | Carla Indira Semedo | Mobilidades e territórios impensáveis. Contranarrativas e afetos

Todas essas histórias fazem de mim quem eu sou. Mas insistir somente nessas histórias negativas é superficializar minha experiência e negligenciar as muitas outras histórias que me formaram. A 'única história cria estereótipos'. E o problema com estereótipos não é q eles sejam mentira, mas que eles sejam incompletos. Eles fazem uma história tornar-se a única história.

Outrossim, a essas narrativas hegemónicas importa unicamente reverberar corpos precários, deshumanizados, não cabendo trazer como Sadyel reitera, "cabo-verdianos aqui que tão a viver muito bem, há filhos cabo-verdianos que já foram ministros, não é, ocuparam altos cargos no governo. Mas, isso também eles não levam". Na entrevista que fizera ao Jo, filho de país cabo-verdianos e descendente do trabalho contratado, instiguei-o sobre o sentido do trabalho contratado, legado dos pais dele. A fala de Jo, mais provocante e instigante que a minha pergunta, recoloca o problema do evento contratado, enquanto uma tentativa de elaboração histórica dos forros de pensar um passado escravista dos cabo-verdianos. Num movimento reverso do que se fala sobre os cabo-verdianos nas roças, Jo rompe e recusa a ideia de um contrato escravo, eleva as habilidades e desenvolturas do povo cabo-verdiano nas artes de lidar com a terra, enquanto o mote argumentativo de terem sidos chamados ao trabalho. Nesse embate de quem somos em função de como fala(ra)m de nós, a fala do Jo inscreve-se num processo de criação de uma outra história em relação ao contrato, visando humanizar os então os cabo-verdianos na condição de contratados:

\footnotetext{
Pra mim não foi contrato. Forro não sabia trabal har não e aqui havia muito terreno para trabalhar. Essas coisas de cacau, portugueses mandou buscar cabo-verdianos pra trabalhar aqui e era trabalho que cabo-verdiano fazia lá. Estas coisas de contrato é forro que diz. Que cabo-verdiano veio contratado, veio num barco. Tempo também não havia muito avião, pra gente vir pra São Tomé ou outro lugar vinha de barco. Esta coisa de vir de barco, gente falava contrato. São Tomé produzia cacau, café, azeite, coco, gente veio trabalhar aqui e praticamente santomense diz contratado. Que gente veio contratado, veio em caixa de lixo... pra mim não é isso. Pra mim, veio ensinar santomense a trabalhar, devido a cabo-verdianos aqui tem bastante cultura de Cabo Verde. Cabo-verdiano sabe dançar funaná, sabe batuko, sabe falar crioulo um bocado, mas normalmente, se não havia estes caboverdianos aqui que veio, gente não sabia trabal har campo, forro não sabia trabalhar só sabia comer.
}

Normalmente, um pouco por todas as roças, quando chegavam cabo-verdianos (integrantes em algum evento), os cabo-verdianos na condição de então contratados, já muito idosos, aproximavam-se de um ou outro visitante e, narravam a sua trajetória, a expetativa de retornar a Cabo Verde, reencontrar a família dos pais, os laços de parentesco, tentando fazer escutar a sua história, questionando o interlocutor se, quiçá, conheceria fulano, sicrano, citando nomes daquelas pessoas e, a localização residencial destes. Esses instantes de rememorar as várias temporalidades e espacialidades que povoam a pessoa cabo-verdiana contratada eram recorrentes nestes/ 
as idosos/as, as quais sinalizavam toda uma economia da fala/silêncio povoados por uma gramática emocional de natureza e de afetos múltiplos e coexistentes: a procura dos laços com um Cabo Verde mítico o qual só escutam falar após décadas residindo no arquipélago santomense; a ânsia de reencontrar um familiar e retornar a Cabo Verde - ainda que isso não signifique um retorno definitivo; e, um desejo de criar naqueles um trabalho de escuta quando narram as histórias das aventuras de viagem, as proezas e os infortúnios. Sendo que, esse recurso retórico e político tende a ser mais recorrente nas roças geograficamente distantes, com fraco ou nulo fluxo de pessoas, ideias e bens à/para a cidade e de visitantes cabo-verdianos. Entendo essa ânsia e os desejos em enunciar as narrativas como um movimento de conceder visibilidade àqueles cujos corpos foram silenciados e, esvaziados nas discursividades "que importam". A todo instante, parece estar em jogo reiterar em como seriam algo mais do que unicamente "os contratados" às roças santomenses, os "perdidos no mato" ou um coletivo que se tornou selvagem e morador do mato. Importa destacar que não somente os cabo-verdianos não santomenses, como também os santomenses nacionais mobilizam estas chaves e narrativas para criar uma qualidade especifica de afeto com aqueles, variando desde um certo repúdio a serem moradores do mato e estarem perdidos no mato, como não-pessoas de direito, quando lhes é retirada a

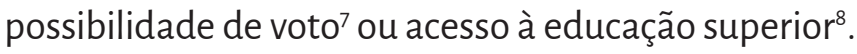

Uma outra chave a ser sinalizada é, a noção commumente veiculada e reconstruída entre as pessoas cabo-verdianas, de que estariam esvaziadas de possíveis práticas e existências africanas e, marcada por uma dita europeização dos modos cabo-verdianos. Noção essa, também, mobilizada quando se narra e se fala dos corpos e pessoas descendentes do trabalho escravizado. A vida no mato, a recoleção dos alimentos naturais, a conformação das casas nas roças ainda nos moldes das senzalas são inscritas nas narrativas e, tentativas de desumanização que os veem "como perdidos no mato" por "viverem ainda no meio do mato", "viverem em senzalas, a comer dos frutos do mato". De frisar que, como tem se mostrado, a dita europeização dos modos cabo-verdianos não se mede pela dimensão fenótipica, mas fundamentalmente pelas práticas culinárias e pelos modos de existência.

Levando a sério quando Cualter afirma: "Eles vêm, só preocupam em encontrar aquelas pessoas que naquela extrema forma de viver vive, então, é aqui que eles pegam, entrevista. E pronto, se eles vivem naquela situação, é verdade que eles não têm boas coisas a dizer, vivem naquelas formas, naquela dificuldade toda, de um pão que falta", percebe-se toda uma tentativa de silenciamento de narrativas de superação e, de vitória entre o coletivo dos cabo-verdianos residentes em São Tomé e Princípe.

Francisca, sexagenária, também beneficiária da pensão do Estado cabo-verdiano, sai todas as madrugadas na companhia do filho para ir buscar, pelo mato adentro, os 'búzios de mato' e revendê-los na cidade. Assim como ela, muitos um
7 Com a independência de São Tomé e Príncipe em 1975, o então governo de MLSTP liderado por Pinto da Costa concedeu Estatuto de Santomenses a todos os trabalhadores que vieram na condição de contratados, incluindo os cabo-verdianos. Em 1991, este direito viria a ser retirado pelo então partido da oposição ADI, quando da sua governância, justificado para muitos, pela ameaça do poder de voto entre os cabo-verdianos, os quais correspondem a um terço da população nacional. $O$ atual governo santomense liderado pelo ADI, (com maioria absoluta nas últimas eleições em outubro de 2014) a partir de um novo decreto em 2015, resolve devolver este direito aos cabo-verdianos: "Recuperam a cidadania são-tomense e dentre outros direitos, o de elegerem e serem eleitos". Mais informação cf. http://www.telanon.info/ politica/2015/03/02/18757/ governo-decide-e-poeem-marcha-campanhade-nacionalidade-paraos-ex-servicais/

8 | Era recorrente entre os interlocutores, enquanto estive em campo, narrativas de que seriam discriminados no acesso à uma bolsa de estudos quando se prefere o santomense ao filho de um cabo-verdiano (facto percetível pelos sobrenomes dos selecionadose os não selecionados), contudo, essa discriminação é mais de ordem da proveniência nacional e, menos enformadas pela racialidade: no caso, ser cabo-verdiano, não importando se fosse de uma tonalidade de pele mais clara ou mais escura que o do forro santomense. 
pouco por todas as roças saem pela madrugada à busca de 'búzios de mato', com candeeiro a petróleo e facão na mão: "não tem mulher, não tem homem, vai só. Não tem que estar parado não, não dá, tem que buscar meio de vida". Bastante usual no interior do mato, por toda a ilha de São Tomé, 'búzios de mato' são grandes caracóis usados no preparo de vários pratos gastronómicos em substituição às outras proteínas animais, pois mesmo na cidade as carnes bdas ovina e suína são as mais caras no mercado, estando o seu consumo, por vezes, limitado aos coletivos com maior poder aquisitivo. Os 'búzios de mato', recolhidos no interior do mato sem custo acrescido aos moradores das roças, constituem a forma de geração de renda de muitas famílias nas roças e na cidade, além de garantir o consumo de uma proteína animal.

Os 'búzios de mato' e o frango constituem as poucas proveniências da proteína animal consumidas nas casas por onde transitei, sendo o peixe em maior proporção de consumo, por haver uma variação dos preços facultando o consumo, por conta do fraco poder de compra dos moradores. Na cidade, o consumo do 'búzio de mato' (como aperitivo nos bares e acompanhamento nos restaurantes populares e domiciliares ou comercializado no mercado central) é mediado pelos moradores das roças que, após os apanharem e os limparem, vendem-nos. Nas roças, nalgumas 'petisqueiras' comercializam 'búzios de mato' grelhados, mas a maioria da população vai à procura dos 'búzios' no mato ou compra a alguém que fora ao mato (vendido a cinquenta mil dobras o quilograma, dois euros) para confecionar pratos tradicionais, apimentados e, à base de leite de coco, azeite de palma (azeite de dendê) ou molho simples. Numa das viagens acompanhando a comitiva da Associação dos Cabo-verdianos e Descendentes em São Tomé - Ké Morabeza, na entrega de donativos (vestuário e calçado), foi-nos mostrado como a relação com a natureza e a proximidade com o mato eram percebidas e acionadas pelos moradores locais.

São Januário, então dependência da Roça Milagrosa (área central da llha, pertencente ao distrito de Mé Zochi), pequena em termos de área quadrada, é habitada em média por trinta a cinquenta moradores. Para os integrantes da comitiva, a situação de São Januário enfatizava a condição dos cabo-verdianos nas roças em como "estão mesmo perdidos no mato de São Tomé, aqui se acontece algo, ninguém vai saber, se não tem contato de móvel, a pessoa está perdida mesmo". O então feitor da roça Nhu Januário, cabo-verdiano de noventa anos, vive com a esposa ainda na casa do feitor, concedida pelo então governo após a independência, sendo os moradores os filhos e os agregados matrimoniais compondo uma família extensa. A maioria tem casa algures próxima da Cidade de Trindade (sede dos serviços administrativos do distrito de Mé Zochi), mas como o campo de cultivo fica em São Januário residem por lá.

Após a visita, a comunidade decidiu fazer-nos o almoço. Maria, filha de Nhu Januário, chegou carregando um balde cheio de 'búzios de mato' recém-recolhidos no mato para limpar e preparar para consumo. Sorrindo, mostrou-nos o balde: "Esse é nosso peixe, mas não comprei! Tirei no mato!". Tiraram carne de coelho salgada, 
cortaram cachos de bananas verdes no terreno ao lado e, agilizaram o almoço: banana verde cozida, búzio e coelho salgado cozido, acompanhado de malagueta pisada e óleo industrial. Quando estávamos a retornar para a cidade, ofereceram-nos cachos enormes de banana verde. Muitos aceitaram e vários cachos de banana foram armazenados na parte traseira do carro. Rindo, disseram-nos: "Cente da cidade, diz que estamos perdidos no mato, que nem animal! Mas como podem ver, aqui temos tudo no mato, é só pegar e comer. Vivemos do que retiramos do mato. Ninguém manda em nós!"

Apesar das dificuldades existentes nas roças, dependendo de roças umas mais acentuadas do que outras, agudizadas por problemas estruturais do país, particularmente a instabilidade política e a pobreza, a ideia de que na roça se passa fome é inconcebível para os meus interlocutores: "na cidade está tudo caro. Muita gente pedindo esmola. Gente da roça está melhor, não precisa comprar muita coisa. Cidade gente passa fome, verdade!". E, o perigo das narrativas únicas elaboradas com as paisagens arruinadas das 'casas de patrão', 'casas de empregados', 'senzalas', as formas de ser e de estar dos moradores locais, é criar uma única história acoplada ao registo de fome e de miséria. Completamente dissociado e irreal, o regime de fome sufoca-se e implode.

Por um lado, as narrativas do Sadyel e do Gualter pontuam as chaves narrativas e os regimes de verdade nos e com os quais se produziu uma história sobre a migração cabo-verdiana, como essa mobilidade cabo-verdiana foi sendo representada e concebida no rol das experiências de mobilidade, tal como o valor acrescido que sempre, quer a historiografia quer memória social do cabo-verdiano, projetaram. Por outro, as experiências etnográficas acima narradas, sinalizam também como essa mobilidade é percebida e relacionada na quotidiano santomense e, nas possíveis tensões existentes entre cabo-verdiano na roça e cabo-verdiano na cidade, como também cabo-verdiano na roça e o forro nacional (esse quer na cidade, quer na roça. Por conseguinte, o ol har no enunciado de que a migração para as roças santomenses não fora o "tipo-ideal" da migração, constrange e impossibilita olhar o mundo deles como eles o percebem e como ele procede. "Viverem em senzalas, a comer dos frutos do mato", faz do mato um território povoado de afetos e relações e "a floresta e os trabalhos nas parcelas concedidas pelo governo São-tomense" traduz a materialização de um projeto de emancipação, de poder fazer a sua casa sem a compra do terreno, poder usar madeira do mato para fazer construção da casa própria.

\section{“NÓS SOMOS CABO-VERDIANOS (...) MAS FAZEMOS COMIDA DIFERENTE DE CABO VERDE! (...) NOSSO TEMPERO É MAIS SABOROSO."-CONTRANARRATIVAS GASTRONÓMICAS}

"Comida daqui é bom. Santomé é bom, viu!"-Dizia-me a Odete enquanto ela ia pisando com um pedra redonda e plana: malaguetas (expressão usual para pimenta) pimenta do reino, folha de louro, cominho, alho e sal para temperar o frango, numa peça de 
madeira quadricular com uma espessura de uns cinco centímetros. A ciência do preparo dos alimentos decorre em várias etapas, as quais traduzem uma certa complexidade no preparo dos alimentos e na feitura dos pratos. 'Pisar a malagueta' revela toda uma desenvoltura e habilidade da pessoa em transformar a mistura dos temperos numa pasta uniforme, com recurso a dois objetos centrais: a pedra e a peça de madeira. A pedra deve ser redonda e toda superfície plana a fim de garantir a uniformidade da pasta, a prancha de madeira ainda que plana, permite pisar os temperos numa pequena cavidade meia-lua feita para esse uso. Com a pedra entre as mãos, segurada pelos dedos, inicia-se um processo frenético e acelerado de pisar os temperos, tendo a atenção da mão e dos dedos não se sujarem com resíduos dos temperos. A avaliação duma 'malagueta bem pisada' é garantida pelo grau de indiscernibilidade dos temperos usados quando espalhados na carne/peixe e após a confeção; igualmente, a habilidade de bem pisar a malagueta junto com a cebola e o tomate.

O uso da malagueta é visceral no preparo e nas práticas de comensalidade quer entre o coletivo dos cabo-verdianos em São Tomé, quer entre os santomenses, tanto que normalmente, quando há alguém a viajar para Portugal, familiares aproveitam para pedir uma encomenda aos familiares em São Tomé, entre as quais a malagueta (pisada ou não). O pai de Mana e Candinho, migrado em Portugal há mais de dez anos, aproveitando um morador de Agostinho Neto de viagem para lá, pediu à Odete que lhe mandasse 'búzios de mato' e, Odete separou também um quilograma de malagueta para Ihe enviar. Após as muitas propostas de como enviar a malagueta, ela decidiu enviá-la toda pisada, para já facilitar o uso, justificando que a vida de migrante em Portugal era muito penosa e corrida..

Normalmente nas casas que percorri e onde acompanhei a feitura dos alimentos, o tempero usado no preparo das carnes e dos peixes, era sempre uma mistura de malagueta, pimenta do reino, folha de louro, cominho, sal e alho. Júlia preparava o peixe gongon com outros condimentos, disse-me que como iria receber amigos do filho para o jantar, o preparo do peixe gongon para assar na brasa ficaria mais saboroso com tomate e cebola pisada: após ter pisado levemente a malagueta, misturando o sal a fim de facilitar na trituração da malagueta, ia juntando paulatinamente pedaços de cebola e tomate (anteriormente cortados em cubos pequenos) à pasta que ia ganhando densidade, até formar uma pasta de cor avermelhada, com a qual em seguida, ela untou nos peixes abertos pelo meio em vertical: no prato bem assado quem visse pensaria ser peixe vermelho pela cor do tempero.

Após ter 'pisado malagueta', com água fervida, Odete realiza outra etapa usual no tratamento das carnes: subtrair da carne o seu sabor animal. Com as coxas de frango em pedaços, Odete deixa por segundos, as coxas na água fervida e rega com um pouco de vinagre. Após essa lavagem, ela espreme limões, espalha a malagueta pisada na carne e em seguida agita o recipiente, deixando de molho. Nota-se um processo de transformação dos alimentos na criação de outras realidades - processos 
transformacionais permitindo outras relações com os alimentos e a natureza. Da malagueta transformada numa pasta em que as sementes desaparecem, como se do cru esses temperos fossem transformados em cozido: "malagueta bem pisada é quando não vê os ingredientes, nem sentimos quando gente come" a carne e/ou o peixe. Como se de um dualismo culinário estivesse em jogo à la Lévi-Strauss, um processo de transformação dos alimentos e com isso potencializar a qualidade da comida, como o processo de lavagem da carne com água fervida e a adição do vinagre e do limão que agem com um antisséptico cultural ao retirar o sabor original da carne e, transformá-la.

Igualmente, o milho, muito comum nas culinárias não só entre os 'descendentes' como também entre os forros, para o preparo da cachupa - prato tradicional da Ilha de Santiago e de Cabo Verde -, da fuba (feita com água fervida com sal, folha de louro e fio de óleo, junta-se farinha de milho, após engrossar, a fuba solidifica e parece um bolo). A cachupa normalmente, é o prato confecionado nos almoços de confraternização entre os dirigentes cabo-verdianos, quando de uma visita oficial aos cabo-verdianos em São Tomé, como também é prato eleito na comemoração das festividades da Independência de Cabo Verde servido aos cabo-verdianos e aos 'descendentes': "As pessoas vêm para cá [no dia 5 de julho] à espera da cachupa de 5 de Julho que é de graça! E todo ano tem a cachupa boa". Entre os 'descendentes', era aceite de que foram eles quem trouxe a opção de usar milho e, a confeção da cachupa cabo-verdiana para São Tomé, com a migração contratada, paulatinamente incorporada pelos forros nos seus regimes alimentares.

Na véspera de Natal passei na casa de LúcialMarcelina. Marcelina estava sentada a limpar peixe, enquanto Lúcia varria a casa9. À entrada da casa, encontravam-se espalhadas espigas de milho dentro do mosquiteiro, para secarem ao sol, disse-me a Marcelina e depois seria feita a cachupa do Natal. O milho veio do campo do Jo ("meu homem" diz Marcelina) e além do milho, outras verduras que ela vende na Praça, na Cidade. Para além da cachupa, a mãe delas (antes de viajar para Cabo Verde em 2013) fazia outras comidas derivadas de milho, usuais em Cabo Verde e incorporadas na dieta alimentar dos 'descendentes': cuscuz, xerém, camoca, ensopado de frango com bolinhos de milho, sopa de rolón e, a fuba -essa última, a única dentre as outras ainda confecionada. Um pouco por toda a Agostinho Neto aproveita-se o milho unicamente para a feitura da cachupa, pois como não existe na comunidade uma máquina de triturar e, 'pisar milho' para fazer fuba é demais desgastante, o que faz com que optem por pisar unicamente com o intuito de separar o farelo do grão de milho, para o preparo da cachupa. À comida e às artes da cozinha, os meus interlocutores demandavam e enalteciam o diferencial das suas artes às 'feitas em Cabo Verde'. E, de

9| É usual tanto na cidade quanto na roça, a vassoura artesanal, comercializada no mercado, um molho de varas de bambu, para varrer tanto o interior da casa quanto o quintal. Nas classes com maior poder aquisitivo, a vassoura industrial. que em Cabo Verde e por se estar em Cabo Verde circulam convenções de conceber a comida e de prepará-la as quais foram ganhando, paulatinamente, variações outras entre os cabo-verdianos e os seus 'descendentes' nas roças. 
Nós somos cabo-verdianos, falamos crioulo mas fazemos comida diferente de Cabo Verde. Nosso tempero é mais saboroso, quando vou pra lá, levo meus limões, malagueta toda pisada num bule, banana, folhas para fazer calulu, levo peixe fumado também. Quando cozinho, junta gente na porta, para meu irmão oferecer comida. Falam 'Dona Deolinda comida de Santomé é bom, saboroso. Vocês cozinham bem'. Quando estive em Portugal acompanhando meu filho [enviado pela junta médica], fiquei na casa do meu irmão e, sempre que podia, cozinhava. Uma vez ele levou cachupa que fiz pra almoçar no trabalho, ele falou que ninguém quis mais comer comida deles, de tão cheiroso e saboroso que estava a cachupa, que nunca tinham comido uma cachupa tão boa ${ }^{10}$. (Deolinda)

A cachupa daqui é mais saborosa que de Cabo Verde, aqui refogamos bem, temperamos muito bem. Fica bom mesmo. Eu por exemplo não habituei com caldo de peixe [prato gastronómico cabo-verdiano], já comi mas não sei fazer, minha mãe não me acostumou com isso. Não gosto muito, também. (Lúcia, 29 anos)

Desta feita, se por um lado, o fluxo de pessoas cabo-verdianas na condição de contratado nos navios desde os dois principais portos de Cabo Verde foi sendo costurado pelas e com as artes culinárias cabo-verdianas, as quais percebem-nas como esvaziadas de matrizes culinárias africanas, pela ausência do intenso sabor da malagueta, das folhas nos preparos de pratos e outros frutos, por outro, as socialidades gastronómicas dos que vieram naqueles navios e das gerações subsequentes viriam a criar outras artes.

O óleo de palma - óleo de dendê das plantações de palmeira do país e produzido a nível nacional - com leite de coco, o uso diário das malaguetas, pimenta do reino e cominho, pau de pimenta e ossami - "sem malagueta comida fica frio", sem gosto" - as múltiplas variedades de banana, a fruta-pão, o tubérculo matabala, os preparos de tempero e da proteína animal (carne, peixe e 'búzio de mato') alimentação à base de variadas folhas (de mandioca, maquequê, entre outras) seriam substanciais na socialidade gastronómica dos 'descendentes' em São Tomé, criando artes culinárias 'à moda da terra'. Expressão em português santomense, 'à moda da terra' é uma adjetivação usual para aludir às formas tradicionais de confecionar alimentos do forro santomense, apropriado também pelos 'descendentes' cabo-verdianos nas roças e na cidade. Evitando toda e qualquer homogeneização possível, as artes culinárias 'à moda da terra' aproximar-se-iam às matrizes africanas quer no processo de feitura, quer nos condimentos e nos ingredientes usados.

Também, a banana - muito usual em São Tomé e de produção nacional - nas variações em banana-pão, banana prata, banana maça, banana-anã, banana ouro, banana graomichel que são quando verdes e sempre usadas na culinária: ou fritas ou cozidas; quando amadurecidas as bananas prata e maça são usadas como fruta e a banana pão quando amadurecida é assada na brasa, mas em momento algum são usadas no preparo de uma caldeirada ou de ensopados. A banana é sempre um acompanhamento a substituir o arroz e quando é assim vem combinada com um

\begin{abstract}
10| Originalmente em crioulo cabo-verdiano: "Nos e cabu-berdianu, nu ta papia crioulu, ma nu ta fazi cumida di otu stilu ki Cabo Verde. Nos temperu e más sabi, ora ki un ta bai Cabo Verde, un ta leba nhas limon, malgueta pisadu na garrafinha, banana, fodjas pa fazi calulu, un ta leba pexi fumadu també. Ora ki un cuzinha, guentis ta djunta na porta kasa, pa nha irmon das bokadu. Es ta flan: cumida di nós é sabi Nhos ta cuzinha sab propri. Kandu un bai Portugal ta kumpanha nha fidju na djunta médica, un fika na kasa de nha irmon, sempre ki un ta daba, un ta cuzinhaba. Un bés el leba cachupa ki un fazi pa almoça na trabadjo, e flan ma ninguém mais ka kis cumé sés cumida pamodi cachopada sta cu cheiru sabi, ki nunca es tinha cumido cachupa sabi si".
\end{abstract}

11 A categoria é recorrente em alusão a um espaço sem animação, parado ou quando a comida está sem pimenta ou com pimenta fraca, referindo menos à temperatura $\mathrm{e}$ mais à pungência, como nos avança Vivaldo C. Lima (2010: 128) na sua análise à cozinha baiana alusiva ao uso fraco ou nulo de pimenta 
molho (de carne ou peixe) oleoso. O preparo da banana é muito comum nas roças e na cidade, mas muitos - jovens ou adultos - preferem por vezes o arroz à banana ${ }^{12} e$, que ao sobrar é usado para alimentar os animais de criação (porcos, galinhas).

$\mathrm{Na}$ maioria das vezes, quando se fazia banana ou fruta-pão assada com algum molho degustava-se com as mãos: quebrando os pedaços de banana/peixe e molhando-se no óleo com malagueta. Por ser uma deglutição crua do óleo, os coletivos com maior poder aquisitivo, substituem o óleo industrial pelo azeite de oliva também importado. Aparentemente, há toda uma ciência em usar algum tipo de óleo nesse prato, pois a combinação, além de tornar o prato mais saboroso, facilita a ingestão da banana ou da fruta-pão cozida, por 'ser seco'. Tanto entre os forros, como nos 'descendentes', esse tipo de combinação do molho oleoso com a fuba, banana, matabala ou fruta-pão, na variação frita, assada ou cozida, é categorizada de 'comida seca' que contrapõe aos ensopados (calulu, guisado de peixe, guisado de feijão ou de frango, entre outros) que são 'comida líquida'. Contudo, a 'comida líquida', caso dos ensopados e guisados, em momento algum é produzida com a banana, pois essa constitui o único vegetal degustado seco, sem adição de caldo algum. Além disso, qualquer variação de caldo é sempre encorpada com uma pasta de farinha de trigo, ficando mais espesso e sempre acompanhado de arroz, que também pode acompanhar o molho, mas quando é assim fica mais um cozido, sem acréscimos do óleo para formar uma gordura. Quando a carne ou o peixe são confecionados para cozido ou para um molho oleoso, normalmente são acompanhados de três vegetais cortados em tiras finas em pouca quantidade: a cenoura, o feijão-verde e a pimpinela (chuchu) e quando a pimpinela for em menor quantidade que o habitual, rala-se para ajudar também a engrossar o molho.

Como referi, a banana normalmente é confecionada sozinha como acompanhamento e não no caldo como é prática entre os cabo-verdianos não santomenses. Era perceptível que, entre os meus interlocutores e as minhas interlocutoras, seria impensável conceber e saborear 'uma comida líquida' sem adição de alguma farinha, tampouco uma combinação inapropriada comer um caldo ou cozido de peixe, ademais se esse for acompanhado da banana, o que reverbera o ceticismo deles à qualidade das habilidades gastronómicas dos outros cabo-verdianos não santomenses e, ao diferencial deles naquela culinária. Sentimentos e/ou manifestações de repúdio à imagem de um dos pratos da gastronomia cabo-verdiana: caldo de postas de peixe com banana verde acompanhado de arroz, era muito frequente não só entre os 'descendentes' na roça, como nos da cidade, como a experiência da Manuela sinaliza.

Manuela nasceu e cresceu em Budo Budo (arredores da cidade), filha de país cabo-verdianos só veio a conhecer Cabo Verde quando fora fazer uma graduação em 2007 (tendo retornado para São Tomé em finais de 2012) e, nesse encontro descobre o caldo de peixe. Com uma expressão de nojo visível, conta-me que a única coisa a que nunca se habitou a comer, enquanto viveu em Cabo Verde, fora o caldo de peixe
12 | Não só na roça, como na cidade o consumo do arroz tem superado o consumo da banana. Pelo facto do arroz ser importado, a maioria das vezes vendido pelo Japão, o seu custo por vezes ultrapassa o poder de compra do povo, e por conta disso, os governos (o anterior e o vigente) têm procurado mecanismos de aumentar a produção nacional da banana e superar o seu consumo para garantir uma dieta alimentar mais substanciada do povo. Contudo, muitos reclamam de que na verdade seria "só demagogia, pois a elite mesmo não usava a banana, só arroz e quer o arroz só para eles". 
com banana verde, mesmo sem banana, beber o caldo líquido seria de 'muito mau gosto'. Nesse encontro com Cabo Verde, mesmo quando participava em convívios ou ia à casa de amigos e, servia-se esse prato, ela sempre pegava peixe e arroz e outras hortaliças se houvesse, sem o caldo e a banana. Nota-se a presença de relações dialéticas em que para os 'descendentes' cabo-verdianos, as artes culinárias permitem demarcar lugares existenciais, pois, ao mesmo tempo que, o território Cabo Verde aparece como 'um país bom', essa diáspora elege as artes da cozinha "à moda da terra" enquanto um artifício de diferenciação e, formas outras de criar a pessoa cabo-verdiana no arquipélago santomense.

Numa tarde ensolarada, pouco mais das treze horas, ao lado do 'jardim' estavam algumas mulheres à volta da Ruth que voltara da cidade com vários peixes para vender em Agostinho Neto. Ruth é 'palaiê' (expressão em crioulo forro para peixeira) e como ela, outras moradoras de Agostinho Neto vivem da revenda do peixe, percorrendo as 'senzalas' com um balde grande sobre a cabeça, normalmente a partir das quinze horas. Dependendo dos preços da revenda, as mulheres decidiam o que preparar para o jantar. Lúcia e Ita cada uma com o peixe atum na mão, caminharam para o quintal delas, enquanto Ingrácia parava o Wagner para levá-la de moto à vila, tentando comprar peixe mais barato, disse ela. Enquanto cada uma, em frente à sua porta, sentada numa pedra limpava os peixes, Ingrácia chegou com peixe bideon. "Vais fazer o peixe como, Ingrácia? Uma vez comi caldo de bideon. Aqui fazem sopa com peixe?" - Perguntei. Ingrácia e Rony param estupefactas e exclamaram "sopa de peixe? Isso é como?" Lá expliquei como fazíamos em Cabo Verde, que também fazíamos caldo de bideon. Desataram a dar gargalhadas, em meio a zombaria: "Caldo de bideon, credo, fica como?" Nada adiantou frisar como era delicioso e, dos efeitos terapêuticos, diante da reticência delas. Nisso, o pai da Marcelina que se encontrava a jogar baralho com Jo, Eleutério homem de Ingrácia e Altino, exclamou:

\footnotetext{
Cabo Verde vocês tem mania de fazer comidas sem gosto. Uma vez, veio uma senhora de Cabo Verde e fez cachupa. Sôra cachupa ruim. Não refoga carne. Cente é cabo-verdiano mas a gente cozinha moda daqui, à moda da terra. Não fazemos aquele caldo de peixe, colocar banana dentro de caldo e comer! Nada! Água no peixe só, nada bom!
}

Semanas após esse episódio, Ingrácia zombava e, criava brincadeiras jocosas: "Então, comeu já teu caldo de bideon? Ficou como? Traz pra gente provar?", tal como a Rony: "Cente disse que lá vocês não pisam malagueta, alho fica cru no tempero. Credu, assim fica sem gosto! Coisa tempera verdade?!”.

Ainda que como vários estudos sobre a diáspora cabo-verdiana (Pedro Cóis, 2008; Évora \& Grassi, 2007) defendem que toda a comunidade diaspórica procura a terra ancestral, criando "comunidades imaginadas" à la Benedict Anderson (1983), uma recriação e reinvenção de uma comunidade cabo-verdiana imaginada e 
vivenciada nas socialidades, interrogo-me da qualidade hermenêutica e heurística dessa experiência e, de sua instrumentalização entre os meus interlocutores. Creio que aos meus interlocutores, às artes culinárias interessa menos rememorar ou recriar um Cabo Verde e, mais pensá-las como um locus onde outros movimentos estão sendo criados. Em como as artes culinárias e as práticas de comensalidade enformam culturalmente as suas corporeidades, demarcando dos cabo-verdianos na condição de contratados e criando-se noutra categoria: "santomense descendente de cabo-verdianos". Quando o pai da Marcelina recusa a cachupa à moda de Cabo Verde, ou com a criação das narrativas jocosas, está em jogo mostrar o São Tomé que acolheu os seus pais quando das fomes e, virou o território deles: confecionar uma cachupa boa 'à moda da terra', fazer um molho de peixe salgado com banana, sendo simultaneamente 'descendentes' e, criando-se nesse movimento sem se preocupar em resgatar ou em monumentalizar as práticas de cozinhas cabo-verdianas ipsis verbis.

Como frisam, "somos descendentes dos cabo-verdianos que vieram contratados de Cabo Verde, não somos cabo-verdianos nascidos [em Cabo Verde]". Outrossim, para os meus interlocutores importa marcar o lugar das artes culinárias nas suas socialidades, em que mesmo sendo filhos e/ou 'descendentes' de cabo-verdianos se demarcavam e desacreditavam da qualidade gastronómica cabo-verdiana e, se vangloriavam das artes e cozinhas por eles confecionadas 'à moda da terra'. Ainda que como Deolinda reitera se veem como cabo-verdianos pois falam crioulo, as artes da cozinha possibilitam e fabricam outras ontologias.

Fazemos comida diferente de Cabo Verde. Nosso tempero é mais saboroso, quando vou pra lá, levo meus limões, malagueta toda pisada num bule, banana, fol has para fazer calulu, levo peixe fumado.

O encontro com o território Cabo Verde fa(e)z emergir diferenciações de práticas e modos existenciais: quer nos modos de preparo dos alimentos em Cabo Verde em que o tempero é espremido e não pisado, a carne fresca é lavada na água corrente e em seguida temperada e não na água fervida com vinagre como se faz em São Tomé; a comida quando líquida na culinária cabo-verdiana é um caldo líquido sem algum acréscimo de farinha para engrossar e o molho é mais espesso e com menos óleo. Igualmente na paisagem das espacialidades do arquipélago cabo-verdiano onde as bananeiras não perfazem nem a paisagem urbana nem a rural de Cabo Verde, estando limitada aos espaços agrícolas rurais o cultivo de bananeira. A banana d'água e a banana maçã (as únicas variações de bananas) usadas unicamente como fruta quando maduras e a banana d'água quando verde no complemento do caldo de peixe, em nenhum momento um acompanhamento. Outrossim, na presença das palmeiras pelo mato adentro santomense, donde se extrai o delicioso vinho de palma e o óleo de palma, ambos inexistentes em Cabo Verde, quando muito trazido dos países da Costa do Continente (Nigéria, Senegal, Guiné Bissau, entre outros), no fluxo 
migratório. Em certa medida, antevejo desencantos nas narrativas deles, como se o Cabo Verde de que tanto os pais e avós fala(va)m não reverberasse a africanização da qual eles se orgulham, face às artes culinárias 'frias', insossas, uma europeização escondida e tão reivindicada pelos cabo-verdianos que eles não defendem.

Carla Indira Semedo é doutora em antropologia social pela Universidade Federal do Rio de Janeiro/Museu Nacional, mestre em antropologia social pela Universidade Federal do Rio Grande do Sul e graduada em sociologia pela Universidade Jean Piaget de Cabo Verde, onde atua como professora auxiliar. Áreas de interesse: práticas de cura, musicalidades, diáspora cabo-verdiana em São Tomé e Príncipe, e memórias coloniais.

CONTRIBUIÇÃO DE AUTORIA: Publicou "Musicalidades das cabo-verdianas nas roças de São Tomé e Príncipe" e "Noções estéticas na performance do batuko: experiência etnográfica entre as batukadeiras de São Martinho Grande (Ilha de Santiago-Cabo Verde)".

FINANCIAMENTO: Bolsa Capes PEC-PG.

\section{REFERENCIAS BIBLIOGRÁFICAS}

ANDRADE, Elisa Silva. As ilhas de Cabo Verde da «Descoberta» à Independência Nacional (1460-1975). s/d. París, Editions L'Harmattan.

CARREIRA, António. 1977. Classes sociais, estruturas familiares e migração em Cabo Verde. Lisboa, Ulmeiro.

CARREIRA, António. 1983. Migrações nas Il has de Cabo Verde. $2^{\text {a }}$ edição. Lisboa, CEE/ICL.

CARREIRA, António. 1984. Cabo Verde: aspectos sociais, secas e fomes do século XX. Lisboa, Ulmeiro.

DOS ANJOS, José Carlos Gomes. 2006. Intelectuais, literatura e poder em Cabo Verde: lutas de definição da identidade nacional. Porto Alegre, UFRCS editora.
ÉVORA, Iolanda e GRASSI, Marzia (org). 2007. Cênero e Migrações cabo-verdianas. Lisboa, Instituto de Ciências Sociais da Universidade de Lisboa (ICS).

FERNANDES, Gabriel. 2002. A diluição da África: uma interpretação da saga identitária cabo-verdiana no panorama político (pós) colonial. Florianópolis, Edufsc.

FOUCAULT, Michael. 2013. Arqueologia do Saber. Rio de Janeiro, Forense Universitária.

FURTADO, Claúdio. 1987. Cénese e Reprodução da classe dirigente em Cabo Verde. Praia, ILCD.

GÓIS, Pedro e MARQUES, José Carlos. 2008. "Práticas transnacionais dos imigrantes cabo-verdianos em Portugal”. In CÓı́S, Pedro 
ARTICo | Carla Indira Semedo| Mobilidades e territórios impensáveis. Contranarrativas e afetos

(org.). Comunidade(s) cabo-verdiana(s):

as múltiplas faces da imigração cabo-

verdiana. Lisboa, ACIDI, pp. 87-104.

SILVEIRA, Onésimo. 1968. Consciencialização na literatura cabo-verdiana. Lisboa, Edição

Casa dos Estudantes do Império.

TROUILLOT, Michel-Rolph. 1995. Silencing the Past: power and the production of history. Boston: Beacon Press.

VIEIRA, Henrique de Santa Rita. 1951.

"Mão de obra cabo-verdiana para S.Tomé".

In: Cabo Verde. Boletim de Propagandae

Informação, Praia, Ano II, n. ${ }^{\circ}$ 23: 29-32.

\section{MATERIAIS CONSULTADOS}

ADICHIE, Chimamanda. 2009. The danger of a single story. TedGlobal, 2009. Disponível em: <http://www.ted.com/talks/ chimamanda_adichie_the_danger_of_a_ single_story $>$. Acesso em outubro de 2012.

CARDOSO, Domingos. 2010. "Pelas roças de São Tomé e Pincípe: do nunca visto ao nem visto", Jornal A Nação, CXXXVI, pp. 23-27.

Código do Trabalho Rural do Ultramar Cabo Verde (27/04/1962). Decreto-Lei de 1903. Boletim Official, São Thomé, IX.

Recebido em 31 de janeiro de 2019. Aceito em 25 de novembro de 2020. 